\title{
An Example of Pragmatic Analysis in Natural Language Processing: Sentimental Analysis of Movie Reviews
}

\author{
Sütçü C.S. ${ }^{1}$ \\ Aytekin C. ${ }^{2}$
}

\author{
${ }^{1}$ Cem Sefa SÜTÇÜ, Marmara University, (Turkey) \\ e-mail: csutcu@marmara.edu.tr \\ ${ }^{2}$ Çiğdem AYTEKIN, Marmara University, (Turkey) \\ e-mail: cigdem.aytekin@ marmara.edu.tr
}

\begin{abstract}
Natural Language Processing (NLP) studies are one of the most exciting applications of artificial intelligence and it is foreseen that NLP will cause new and revolutionist changes in humancomputer interaction. In this aspect, NLP is analyzed in five different segments: Phonology, Morphology, Syntax, Semantics, Pragmatics Analysis. In this paper, a sentimental analysis will be conducted using movie reviews left by users on beyazperde.com. The sentimental analysis allows to automatically draw conclusions about the mood from text data. Thus, numerous reviews left on a movie can be sorted as a positive or negative mood without the need of reading all of them one by one. The ability to sort the reviews automatically according to their mood is invaluable to those who are considering watching the said movie, actorslactresses, producers and advertisers. Such application arms media companies with new and improvable opportunities to create effective strategies. In this aspect, viewer expectations can be analyzed, and this information can be utilized for the upcoming program projects. Importance of communications and information technologies is undeniable. It is foreseen that this paper will aid the production of information processing in Turkish.
\end{abstract} Reviews.

Keywords: Natural Language Processing, Artificial Intelligence, Sentimental Analysis, Movie

\section{Introduction}

Natural language processing is one of the main issues of artificial intelligence. Although it has shown an increasing trend around the world especially in the last three years (2016-2019), it can be said that its history is as old as the emergence of computers. Therefore, natural language processing studies have also been mentioned with different names in this historical process: Computational Language Science, Statistical Natural Language Processing and so on. The basis of these different nomenclatures lies in the diversification of the work that can be done through natural language processing over time. Today, these works are categorized in different ways as the field expands and natural language processing is further developed into sub-branches.

Language is the most basic means of reconciliation among living things. In this context, a classification related to communication types is examined within the framework of written language and oral language. According to Gleason; written language, verbal language, and associated components (source and receiver) are synergistic systems consisting of individual language domains that form a dynamic inclusive whole. These individual language domains can be studied at five levels: phonology, morphologic, syntactic, semantic and pragmatic. Pragmatic analysis refers to the rules of language for an interview (commentating/commenting) and wider social situations. It also includes on the listening side of the spoken language, "understanding of the social aspects of language" and on the speaking side "social use of language". In the written language, on the reading side, it includes " understanding the perspective, the needs of the user and so on" (Gleason, 2005). This study focuses on the written language of pragmatic analysis. 
On the other hand, thanks to the interactive feature of the internet environment, users can express their opinions and make comments by taking part in the channels of interest. More importantly, since they are willing to take part in this environment, it is possible to easily reach clear and transparent views that are difficult to obtain in other ways. Therefore, the emotions in these written texts can be analyzed and the information obtained can be used according to the needs. However, considering the size of the data flowing in these environments, it becomes difficult or even impossible for emotion analysis to be performed by manpower. Therefore, the analysis should be done automatically with artificial intelligence methods. Sentimental analysis emerged from this requirement as one of the sub-fields of natural language processing related to written language.

Interpretations are at the center of almost all human activities because they are key elements of our behavior. Organizations and businesses always want to create public opinion about their products and services. In addition, individual consumers want to know the opinions of their current users and the opinions of others before purchasing a product or service. When an organization or business needs public or consumer views, it creates surveys and focus groups. Obtaining these views is a great business for marketing, public relations, and political campaign companies. This limitation of social networks, forums and so on. environments. Interpretations in these environments are now included in the decision-making processes of both the individual and the organizations and businesses. For individuals, the limitation of family and friend level has disappeared. An organization or business may not conduct surveys and focus group research. This is because there is an abundance of such data in order to collect public opinion (Liu, 2012, 8). The sentimental analysis assumes the task of extracting information from such data, enabling the automatic deduction of their emotions from user reviews.

In this respect, in the study, a sentimental analysis of the user reviews shared on the movies on beyazperde.com website was made using a sample data and the results were evaluated with sensitivity measure.

\section{Literature Review}

\section{Natural Language Processing Applications and Turkish Language}

Natural language processing is an interdisciplinary field that is based on the processing of natural language with artificial intelligence technologies for an area to be benefited. It combines expertise in linguistics, design, communication science, software engineering, and data science. Apple's Siri for natural language processing applications, IBM's Watson, ChatBots developed for different sectors, search engine technologies that can be tailored to the needs of the user, robot journalism, and expressions in text with technologies using deep learning techniques. Popular examples include robot narrative and narrative verbal expressions on Instagram. Nowadays, natural language processing is expanding and developing with the rapid increase of big data which includes different forms of media such as text-sound-image. Figure 1 shows possible working topics in the field of natural language processing.

Natural language processing can be used as a useful area, for example for detecting false news in revealing fake news. One of the recent studies on this subject belongs to Traylor and Straub (Traylor \& Straub, 2019: 445). Authors have tried to determine the possibility of fake news texts by using natural language processing methods, considering that deceptive content affects models such as idea formation, decision making, and voting and this creates a worldwide information accuracy and integrity problem. According to them, most of the fake news is primarily planted on social media channels such as Facebook and Twitter. From this point of view, they made a fake news identification study using Bayesian algorithm and evaluated their performance. The resulting transaction sensitivity is $63 \%$ effective in assessing the possibility that a news text is fraudulent. 


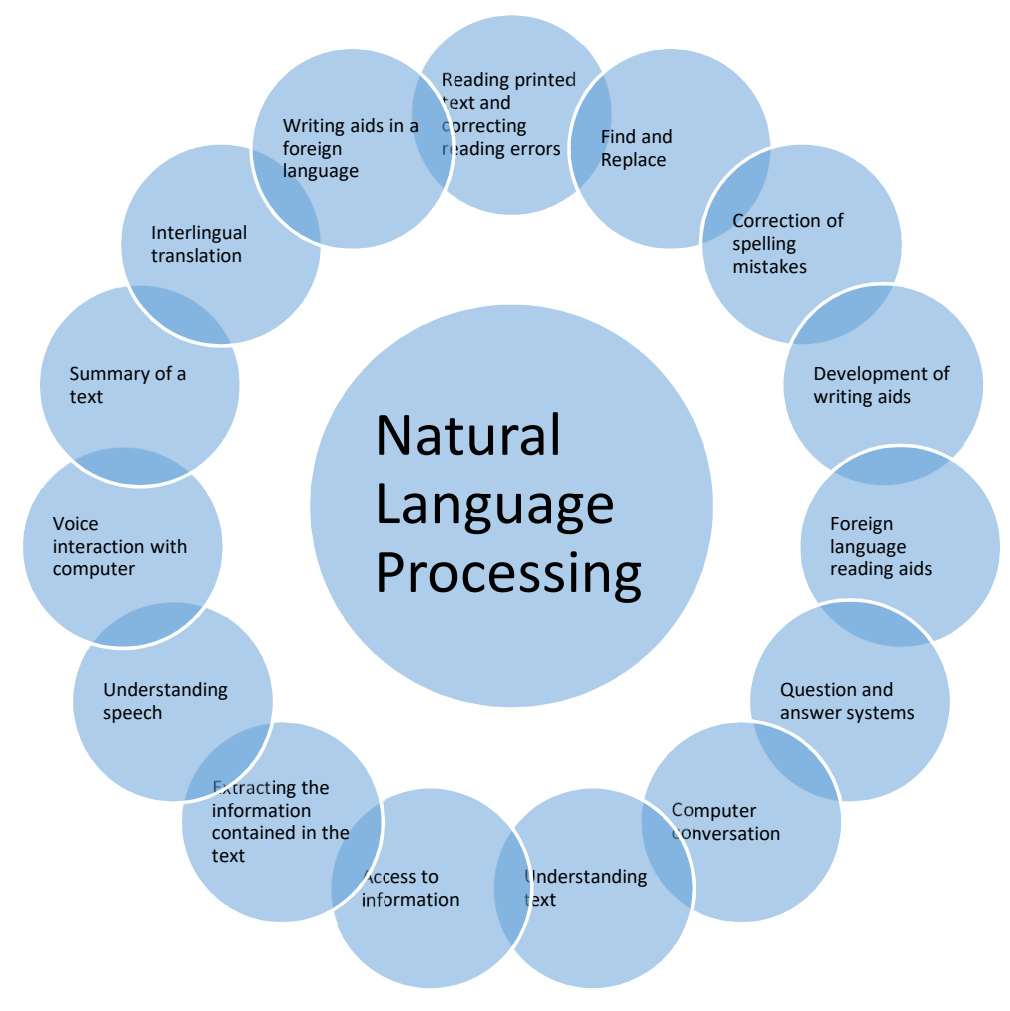

Figure 1: Natural Language Processing Topics (Adalı, 2013: 4)

Withanage and colleagues developed a system based on the assumption that voice-based navigation systems play an important role in filling the gap between man and machine. They overcame the user's difficulty in receiving and understanding voice commands and proposed a mobile navigation application called "direct me", which mentions the main elements such as street names, landmarks, points of interest, intersections, and specifies the route on an interactive interface. Here, the approach of creating the user's preferred route is provided by first converting the audio streams to text and then using natural language processing to obtain navigation-related information. This system can be used as an effective approach to translate natural language instructions into a machine-understandable format (Withanage, Liyanage, Deeyakaduwe, Dias, \& Thelijjagoda, 2018).

In another study, a natural language processing framework was proposed to create natural language interaction in Chinese. Syntax analysis, the proposed assessment method to understand the relationship of change between entity classes in the group, and Bayes-based verb classification are some of the elements of this framework. In addition, a semantic framework of verb types has been established in order to identify the necessary and unnecessary roles for each verb type. As a result, in order to help a robot to understand the instruction in summary terms, a semantic role-playing approach has been proposed with the human-computer interaction module. The method was confirmed by the relevant experiments. The research forms the basis of human-robot natural language interaction (Li, Xu, Qi, \& Ding, 2018: 2171, 2176).

Robot journalism is another natural language processing application and is based on the writing of news by computer software. This requires generalized rules of language characteristics, and journalists should be able to produce the format of the news and words that can be the labels. Today, robot journalism studies are carried out with different perspectives. For example, one study is conducted to determine the attitudes of journalists to adopt robot journalism (Kim \& Kim, 2018: 340), while another study is structured on the construction of text segmentation and custom labeling for natural language processing (Naeun, Kirak, \& Yoon, 2017: 566).

On the other hand, Turkish has several features that present very interesting challenges in terms of natural language processing. Being additive morphology structured language, vowel harmony 
and sentence elements being replaced freely are some of them (Oflazer, 2016: 1). Over the past two decades, a number of resources have been developed that can be used in Turkish natural language processing: Morphological Analysis, Morphological Unification, Statistical Dependency Analyzer, Lexical-Functional Grammar-Based Analyzer, Tree-Structured Corpus, Turkish WordNet, and Turkish Corpus are the most important ones (Oflazer, 2016: 9-10).

One of the biggest projects in Turkish natural language processing is the open-source Zemberek project. Text classification, spelling, orthography, syllabication, finding possible roots and attachments, word generation is some of the applications performed in the project. The first version of the spring was released in 2006. Finally, on 29.10.2018, "0.16.0 text normalization and gRPC (google Remote Procedure Call) server" version was released. The text normalization feature in this release attempts to correct errors in sentences used in social media, forums, and messaging software. For example, the phrase "tmm, yarin havuza giricem ve aksama kadar yaticam :) [ok, I'll enter the pool tomorrow and lay down till evening :)]" can be converted to "tamam, yarın havuza gireceğim ve akşama kadar yatacağım :) [okay, I will enter the pool tomorrow and sleep until evening :)]". This process is important for the success of text analysis (Zemberek, 2019).

Gülşen Eryiğit presented the "Turkish Natural Language Processing Software Chain" platform of İstanbul Technical University at the 14th European Chapter of Computational Linguistics Conference. ITU Turkish Natural Language Processing Web Service (http://tools.nlp.itu.edu.tr/) provides users with automatic update and patch management, ease of communication, easier collaboration, and more. It also provides researchers and students with many levels of natural language processing tools such as preprocessing, morphology, syntax, and entity recognition. Users can communicate with the platform through three channels (Eryiğit, 2014: 1-4).

\section{Sentimental Analysis}

Pragmatic analysis allows you to analyze what the given text basically means. The aim is to draw inferences from the given text. Sentimental analysis is one of the fields of study of pragmatic analysis and aims to reveal the emotions in the given text. Sentimental analysis is a field of study that analyzes users' views, feelings, assessments and attitudes towards entities such as products, services, organizations, individuals, topics, events and their characteristics. The term was first used in Nasukawa and Yi's 2003 study "Sentiment Analysis: Capturing Favorability Using Natural Language Processing" (Nasukawa \& Yi, 2003) (Liu, 2012: 7). The main point of a sentimental analysis is to reveal the emotions contained in the text data. The analysis can be performed at three levels: Document-level, sentence-level, and precision level. All levels have their own procedures and functions. In the first level, the entire document is analyzed according to the general mood. At the second level, the detail data of the comments are expanded. For example, the interpretation of "the screen of this mobile phone is great" indicates a positive feeling for the mobile phone's "screen". At the third level, problems grow, but they are more clearly revealed. Upon completion of all levels, user feedback is displayed (Solangi, et al., 2018: 3).

Sentimental analysis can be done in three ways: machine learning, dictionary-based technique of textual data and a mixed technique that combines machine learning and dictionary-based technical approaches (Rosa, Schwartz, Ruggiero, \& Rodriguez, 2019: 2125). Although the dictionary-based technical form was predominantly used in the study of sentimental analysis, nowadays, studies on all three forms are increasingly continuing. Sentimental analysis is widely used in "voice of the customer" researches of organizations and businesses, measuring the effectiveness of marketing activities and online reputation management. However, there are also areas of use for different purposes. For example, the journalist Terena Bell posted on her Twitter account on 27.06.2017 that Periscopic, a data visualization company developed "Trump Emoti-Coaster" application to measure the moods in Donald Trump's videos (Bell, 2017). Figure 2 illustrates this practice based on the facial expression visual recognition and natural language processing infrastructure. All emotions are derived from the standard video broadcasts using the Microsoft Emotion API. Here, the video is taken as an input and a description of the emotions detected at any given percentage over time. Perceived emotions are emotions that address universally specific facial expressions such as anger, contempt, disgust, fear, happiness, neutrality, sadness and surprises. 


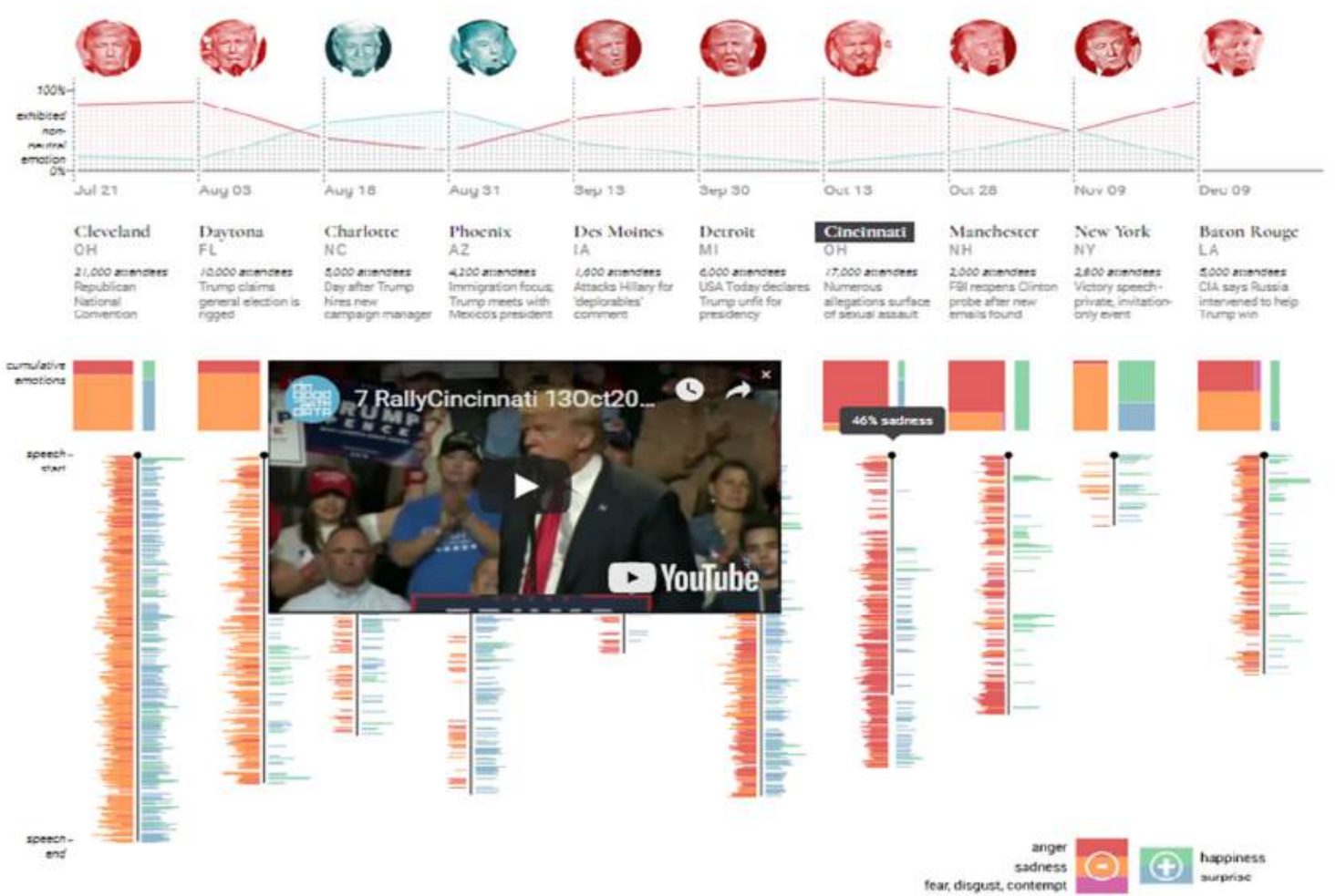

Figure 2: Trump Emoti-Coaster Application

(Periscopic, 2019)

Another area of application of sentimental analysis is applications for monitoring and recommendation systems (RS). This is because social networks, which are widely used today, contain a number of useful data to provide users with a sense of mood for different themes. In their study, Rosa et al. Designed a Knowledge-Based Recommendation System (KBRS), which includes a health monitoring system to identify users with potential psychological disorders, especially depression and stress. According to monitoring results, based on ontologies and sentimental analysis, KBRS is enabled to send happy, calm, comforting or motivational messages to users with psychological disorders. In addition, if a depressive condition is detected by the monitoring system, a mechanism that sends warning messages to authorized persons is included in the system. The proposed method has achieved $89 \%$ and $90 \%$ success in detecting depressed and stressful users, respectively (Rosa, Schwartz, Ruggiero, \& Rodriguez, 2019: 2124).

"On Left on Read" (https://leftonread.me/) is an application that presents users' moods in iMessage and was developed by two students, Teddy Ni and Alex Danilowicz, to monitor their message writing habits (later, seven more students have come to the team). With this application, users can see when they write messages, how they write and who they write. They can see the information and thus they can determine their own emotions depending on time. In other words, they can follow their own speaking habits. The developers of the application state that users can see their relations with their phones and thus feel better (Culver, 2019).

In their study, Ren et al. Started with the assumption that investor sentiment plays an important role in the stock market. Because user-generated text data on the Internet provides a valuable resource for reflecting investor psychology and predicts stock prices as complementary to stock market data. The study integrates sentimental analysis based on a support vector machine into a machine learning method. In addition, the "day of the week" effect was also considered, thus creating more reliable and realistic emotion indices. The findings also indicate that emotions probably contain valuable information about the core values of the entity and can be regarded as one of the leading indicators in the stock market. The model helps investors make smarter decisions (Ren, Wu, \& Liu, 2019: 760). wefeelfine.org is a web-based emotion search engine. It was developed by Kamvar and Harris for dictionary purposes. We Feel Fine is based on a data collection engine. This engine automatically tracks many blocks that collect human emotions every 10 minutes. Blog data comes 
from many online sources. We Feel Fine scans blog posts to collect data on "I'm feeling" or "I feel" expressions. This is an approach inspired by the techniques used in the project "message listening ", a project developed by Mark Hansen and Ben Rubin. Most blogs are hosted by one of several large blogging companies. The URL format of many blog posts can be used to extract the author's name from the entry. Given the author's name, the zigzags can be drawn from the given blogging site to access that author's profile page. The profile page can extract information such as age, gender, country, state and blog author's city. Given the country, state and city, the weather conditions of that location can be subtracted from the time of writing, and most of this information and similar information is extracted. This process is automatically repeated every ten minutes. In general, identification and recording are around 15-20,000 emotions per day. The application panel allowing the viewer to control the sample population on the screen at any time can be used to arbitrarily sort the different populations into substances. The criteria that can be used by any combination are: Happy, sad, depressed, and so on moods, age, gender, weather, location and history (We Feel Fine, 2019).

Kamvar and Harris introduced the emotion search engine in their work titled "We Feel Fine and Searching the Emotional Web. The purpose of the search engine is to gather and reveal emotions at a world level to help people understand themselves and others better. Traditional motivating practices for sentimental analysis are included in consumer research and decision support system tools. However, data on moods can be used to support other research in the social sciences, such as creating scalable computing tools. Such tools have the potential to make a significant impact by allowing social science researchers to carry out cheap and large-scale studies in generating databased hypotheses (Kamvar \& Harris, 2011: 126). Figure 3 shows the sentimental diagram of the emotion search engine.

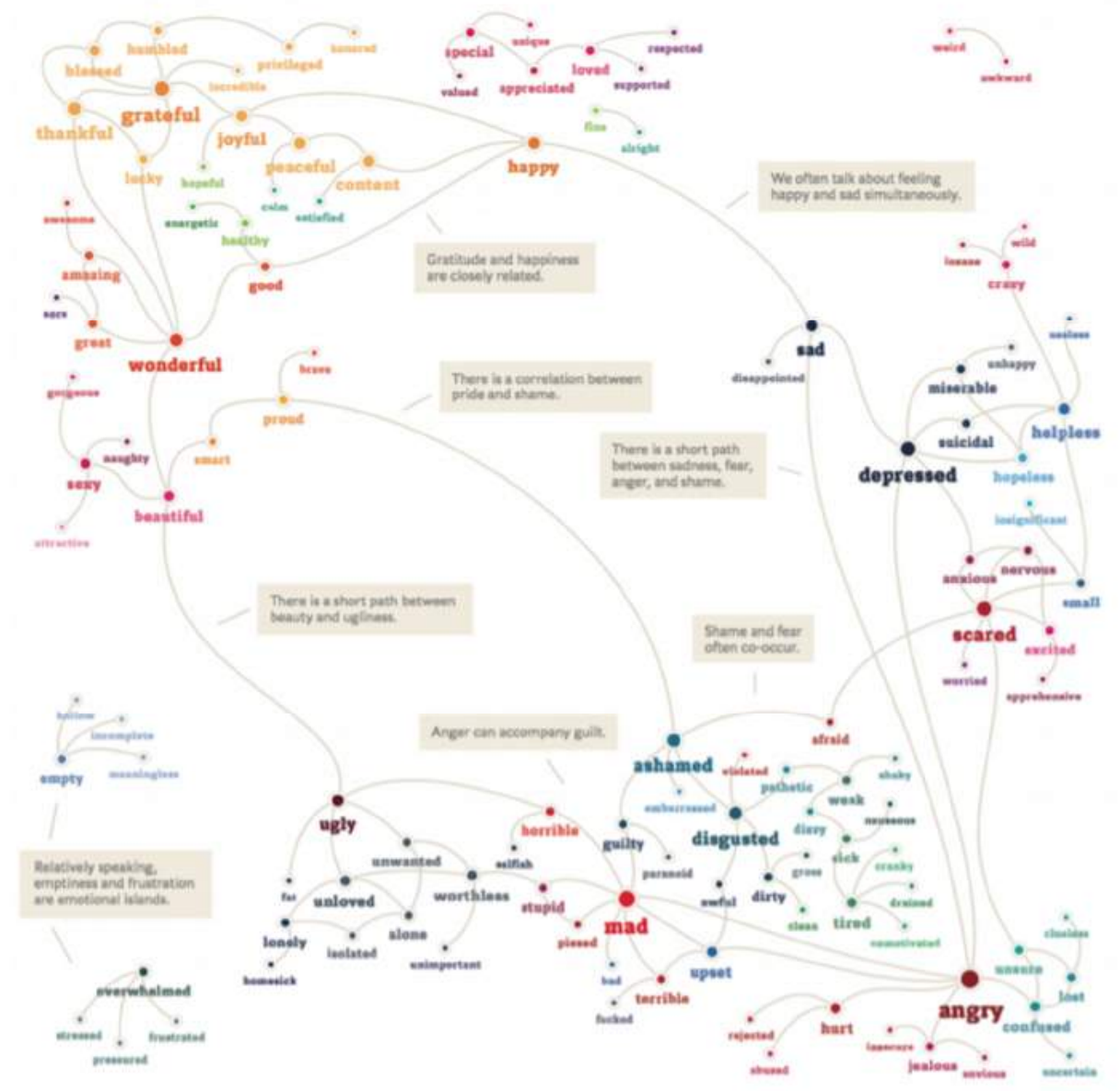

Figure 3: Sentimental Diagram (Kamvar \& Harris, 2011: 127) 
In the literature, there are many studies structured on different languages and methods for the sentimental analysis of movie reviews subject to this study. One of the recent studies is the Indonesian language study conducted by Permatasari et al. Here, both dictionary-based technique and machine learning methods are used for sentimental analysis. These techniques have f-measurement success values of $88 \%$ and $94 \%$, respectively (Permatasari, Fauzi, Adikara, \& Lukmana Sari, 2018: 92). The study of machine learning in Hindi language (Nanda, Dua, \& Nanda, 2018) and a study of a lexical update algorithm in Chinese language (Song, Gu, Li, \& Sun, 2017) are other recent language-based studies.

In the Turkish language, in the study titled "Performance Comparison of Text Representation Methods in the Classification of Turkish Texts", movie reviews were used as a data set such as "news" and "mood" (Amasyalı, Balcı, Varlı, \& Mete, 2012). In their study, Vural et al. Conducted a sentimental analysis of movie reviews in Turkish with uncontrolled learning (Vural, Cambazoğlu, Şenkul, \& Tokgöz, 2013). Kaynar et al. made the sentimental analysis of movie reviews in Turkish using four different algorithms and observed that artificial neural networks and support vector machine algorithms gave better results than other methods (Kaynar, Yıldız, Görmez, \& Albayrak, 2016).

\section{A Research on Sentimental Analysis of Movie Reviews}

\section{a) Purpose and Importance of Research}

This research focuses on the sentimental analysis of movie reviews as an example of pragmatic analysis in natural language processing. In this respect, a sentimental analysis of the shared user reviews about the movies on beyazperde.com was conducted in a sample. The sentimental analysis automatically extracts the results of emotions from text data. Thus, many interpretations can be assigned to one of the positive or negative moods by artificial intelligence methods without having to read them one by one. The success of the assignment includes a comparison of the results automatically obtained with the manually marked results of the sample set and evaluated by the precision measure.

The automatic structuring of feedback on movies through artificial intelligence methods is invaluable for the movie's actors, producers, and advertisers, especially those who intend to watch the movie. Such an application provides new and improved opportunities for media businesses to develop effective strategies. In this respect, audience expectations can be evaluated, and this information can be used as input for subsequent program projects. The importance of communication and information technologies is indisputable today. This study is expected to contribute to the production of information processing in the Turkish language.

\section{b) Sample of the Research}

The sample of the research is a subset of the Turkish movie reviews which are collected randomly from www.beyazperde.com. Data were obtained from http://sentilab.sabanciuniv.edu/wpcontent/uploads/2015/03/TurkishMovieReviews.txt. This address belongs to Sabancı University. Sentiment Analysis Research Group is engaged in the fields of text mining, information acquisition and sentimental analysis research under the title of "Sentilab Project" at Sabancı University. The group draws synergies from expertise in different fields such as machine learning, data mining and natural language processing (Sentiment Analysis Research Group, 2019).

There are user reviews for the movies, 183 of which are negative, 822 of which are positive and 145 of which are objective. Within the scope of the research, only reviews that indicate positive and negative emotions were included. In this way, a database of 1005 reviews were created. This database will be referred to as "Movie Reviews Database-MRD" in the following sections.

Below are two examples of reviews in the MRD that indicate a positive mood:

"I think he definitely deserved the score. I laughed so much, it was beautiful, Adam Sandler was great, again funny. I recommend you watch :)) [bence aldığı puanı kesinlikle hak etmiş o kadar güldüm ki çok güzeldi adam sandler harikaydı yine çok komik izlemenizi tavsiye ederim :))]"

"A quality spectacle that never bored, one of the best of its kind. [hiç sıkmayan kaliteli bir seyirlik türünün en iyilerinden.]" 
The following are two examples of reviews in the Movie Reviews Database that indicate a negative mood:

"I couldn't understand how Janiston starred in such a ridiculous stage movie. I gave it five points for the sake of the beautiful face of Aniston. [janiston nasıl böyle saçma bir sahneli film de rol aldı anlayamadım. 5 puan verdim o da anistonun güzel yüzünün hatırına.]"

"I can tell you that I have an extremely boring movie ... how did they make such an absurd topic, hullo. [son derece sıkıcı bir filim olduğunu söyleyebilirim... saçma bir konuyu nasılda filim yapmışlar maşallah.]"

\section{c) Research Methodology}

An application developed by Aytekin was utilized for automatic analysis of the reviews with artificial intelligence methods in the MRD (Aytekin, 2013). This application has been developed with uncontrolled learning techniques and classifies the text data according to the Naive Bayes Bit Weighting Algorithm rules which in most cases provide effective results. The assignment to emotion states was structured according to the probability values of 4744 adjectives/adverb-based words in the dictionary. The reason for choosing words based on adjective/adverb is since they can best convey the desired mood.

However, since this application was developed based on blog reviews, it was inadequate in evaluating movie reviews. For this reason, 183 negative emotion state reviews and 822 positive emotion state reviews were transferred to a separate database and frequency analyses were performed on word basis. The assumption is that, for example, if a word in the database of 183 negative emotion reviews is at the forefront in terms of frequency and is adjective/adverbial-based, then this word must be included in the dictionary with the corresponding probability value. The same applies to words in positive emotion reviews. In this way, new words were added to the dictionary and a new database was obtained. This database will now be referred to as the "Turkish Movie Reviews Emotion Dictionary-TMRED". In other words, it was envisaged that the words in this dictionary could now represent film interpretations.

What is important here is the probability value of the newly added words. As a result, there are many probability instances between 1-100. For example, will the newly added "even [hatta]" and "times [kez]" words in a positive mood receive the same positive probability values? Or is it not necessary to change the probability values to represent the movie reviews of the words in the old dictionary but not new ones? As the answer to the second question, let us immediately say that the probability values of 5 words had to change. We also discuss the answers to these questions under the heading "examples of erroneous results" of the research. Table 1 shows examples of the words added to the TMRED.

\section{Table 1: Examples of Words Added to Turkish Movie Reviews Emotion Database Glossary}

\begin{tabular}{|l|l|}
\hline Positive Emotional Words & Negative Emotional Words \\
\hline super [süper] & disgrace [rezalet] \\
\hline funny [eğlenceli] & vote [oy] \\
\hline exactly [kesinlikle] & Bayık [unconscious] \\
\hline times [kez] & affect [etkileme] \\
\hline times [kere] & exaggeration [abartı] \\
\hline times [defa] & \\
\hline quality [kaliteli] & \\
\hline even [hatta] & \\
\hline even [hele] & \\
\hline advice [tavsiye] & \\
\hline legend [efsane] & \\
\hline
\end{tabular}




\section{a. Research Findings and Evaluation}

First of all, it is important to note that users use spoken language when writing "reviews" about the movie. Because these environments are what we call "informal" in communication. Therefore, norms such as spelling rules and grammar are often not paid attention. However, this situation causes some problems in the operation of the algorithm. For example, Table 2 shows the different spellings of the word "beautiful [güzel]" in social media (Sütcü \& Aytekin, 2018). If the user chooses an incorrect spelling in the form of "quzel" instead of "güzel", the algorithm will not be able to find such a word in the Turkish Movie Reviews Emotion Dictionary and evaluate its probability value in the calculation. This may cause the review to be assigned a false mood. Different solutions are presented in the literature for this situation. One of them is using wildcards. In this method, often misspelled words are also included in the dictionary. The second and more important one is the spelling check. The Zemberek project, which has been developed in this regard, guides the researchers working in the field of Turkish natural language processing. In this research, the spellchecking of reviews was done manually. Yet, it is possible that the reviews presented to the algorithm are assigned to false emotions without spelling. This way has been taken in order not to compromise the sensitivity measure.

Table 2: Different Spellings of the word Güzel [beautiful] in Social Media

\begin{tabular}{|l|l|l|l|l|l|}
\hline güzel & güzelll & guzel & güsel & güzeel & guselll \\
\hline gzl & gsl & gsel & gzel & qüzel & qusel \\
\hline gzel & quzel & güssel & quselll & qussel & qüsel \\
\hline
\end{tabular}

The Naive Bayes Bit Weighting Algorithm can be summarized as follows:

1. As a first step, reviews are extracted from punctuation and numbers (because only text is required), all are converted to lower case.

2. Each word in the review to be analyzed is compared with the words recorded in the Turkish Film Reviews Emotion Database dictionary and bit weighting is performed; 1 for those found, and 0 for those who do not. The number of repetitions in the review is ignored (algorithms using repetition numbers work on a different principle).

At this point, it would be appropriate to talk about the task of finding a root. Some words in the review, suffixes, etc. may not be included in the Turkish Movie Reviews Emotion Database dictionary. However, this disadvantage could be eliminated with an application to find the roots of words. Since the words in the dictionary are adjective and adverb-based words, they do not have roots. Because adjectives, when used alone are names. Therefore, they cannot take the suffixes (noun suffix, possessive suffix, plural suffix) when they are used as adjectives. Adverbs are non-affixed words; they do not take adjuncts. However, if they are used as names, they may receive adjunct. Therefore, no application has been developed for root discovery.

The flow diagram of the algorithm is shown in Figure 4. All stages are shown in a certain order with a focus on how to go to the solution. 


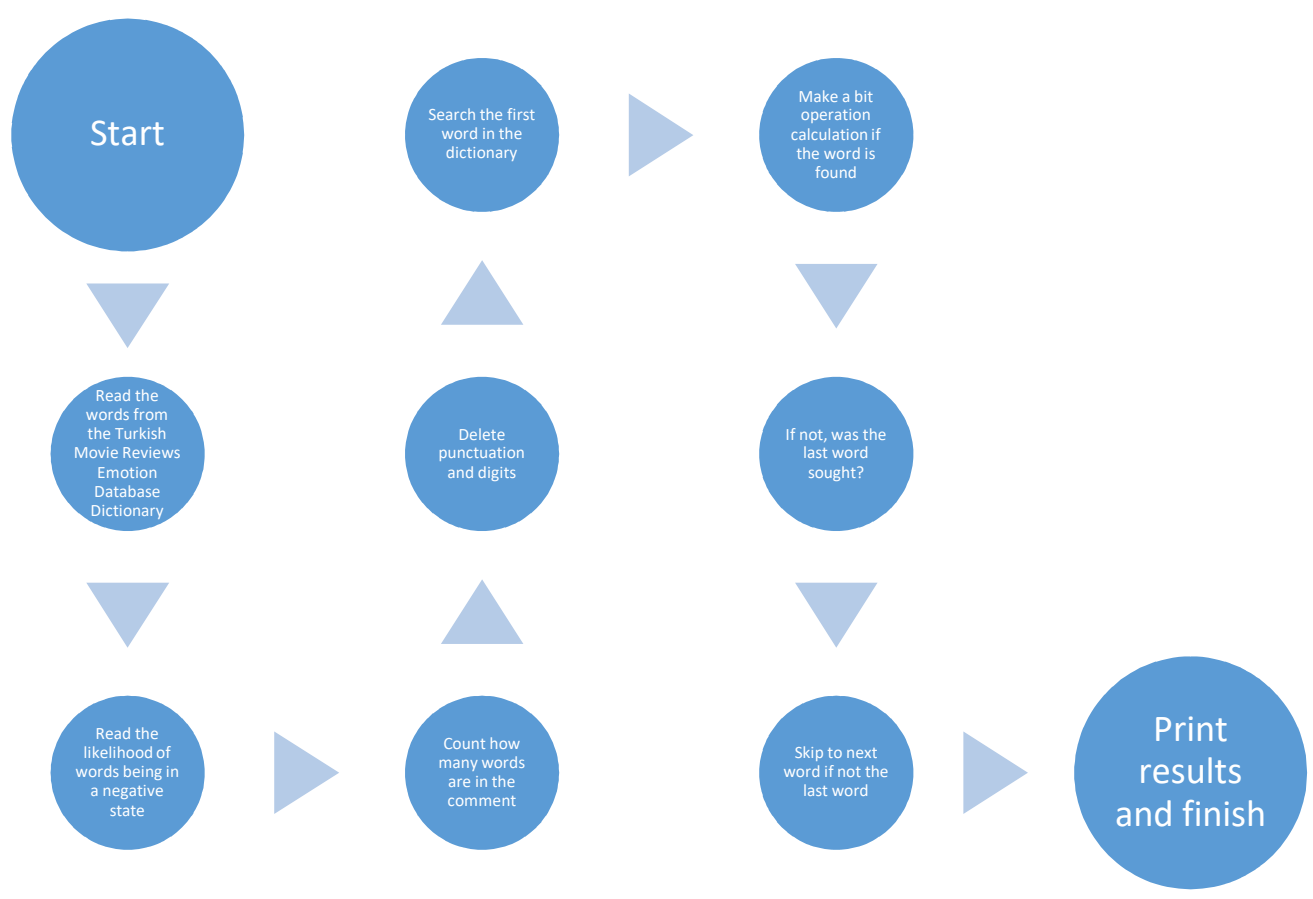

Figure 4: Algorithm Flow Diagram

The algorithm works on the following basis (the larger of the two calculated results will give the emotion state of the review):

Probability of review to be in positive emotion $=1 / 2 *$ (the probability that each word/phrase in the TMRED dictionary will be in positive emotion).

Probability of review to be in negative emotion $=1 / 2 *$ (the probability that each word/phrase in the TMRED dictionary will be in negative emotion).

In the research, the success of assigning the manually marked reviews of the application to the related mood was evaluated with sensitivity measure. Sensitivity measure is one of the most commonly used methods for measuring text classification effectiveness. Table 3 and Table 4 show the results of the analysis of the assignment of reviews to the relevant emotional states with sensitivity measures.

\begin{tabular}{|c|c|c|}
\hline $\begin{array}{c}\text { Number of Reviews } \\
\text { Assigned Correctly }\end{array}$ & $\begin{array}{c}\text { Number of Reviews } \\
\text { Incorrectly Assigned }\end{array}$ & Unassigned Reviews \\
\hline 658 & 142 & 22 \\
\hline \multicolumn{3}{|c|}{ Sensitivity Measure $=\% 80,04$} \\
\hline
\end{tabular}

Table 3: 822 Appointment Results of Positive Emotional State Reviews

\begin{tabular}{|c|c|c|}
\hline $\begin{array}{c}\text { Number of Reviews } \\
\text { Assigned Correctly }\end{array}$ & $\begin{array}{c}\text { Number of Reviews } \\
\text { Incorrectly Assigned }\end{array}$ & Unassigned Reviews \\
\hline 119 & 58 & 6 \\
\hline \multicolumn{2}{|c|}{ Sensitivity Measure = \%65,02 } \\
\hline
\end{tabular}

Table 4: 183 Appointment Results of Negative Emotional State Reviews

On the other hand, Table 3 and Table 4 mention "unassignable" reviews. For example, "I said no more, what a trick [yok artık dedim, ne dümenler dönüyor ya]", while the negative emotional state review was not made. Because no words in this review are included in the Turkish Film Reviews Emotion Dictionary. Because the dictionary consists of adjective/adverb-based words. Accordingly, the 
dictionary needs to be expanded/improved. Reviews that cannot be assigned in the above tables are also considered in the wrong category.

When Table 3 and Table 4 are examined comparatively, it is seen that the success of the assignment is higher in positive mood reviews. One reason for this is that the number of samples of positive reviews is much higher than negative reviews. In other words, words capable of representing positive interpretations could thus be identified at a higher rate.

Another assessment can be based on the number of words of reviews. For example, the average number of correctly assigned negative mood reviews is 41 , while the incorrectly assigned negative mood reviews are 36 words. Thus, short-written negative emotion state reviews may cause false assignments. So, if the review is longer, it can be said to be more accurately assigned to the negative emotional state.

\section{b. Discussions on Examples of Incorrect Results}

The following are examples of reviews that are assigned to the wrong mood in the TMRED for different reasons:

1. "sometimes it was shown on TV often and I saw it as a very sympathetic movie. A film that needs to be watched or not. Meanwhile, Vanessa Paradis is the wife of the beloved pirate Johnny Depp and has two children. Wish them happiness [bi ara tvde sık sık verilen we çok sempatik bi film olarak gördüm izlenmesi gereken ya da gerkmeyen film bu arada $u$ an vanessa paradis çok sevgili korsan johnny deppin eşi rolündedir we 2 adet çocukları vardır mutluluklar dileriz]".

The above review is marked manually as a positive emotion. However, the application assigned this review to a negative mood. In this review, the words in the dictionary and the probability values are as follows:

very [çok] $\quad 0,111991088$

sympathetic [sempatik] 0,462799907

need [gereken] $\quad 0,606238745$

beloved [sevgili] $\quad 0,718546845$

often [sık sık] $\quad 0,735649124$

In this analysis, words represent review, but the probability values need to be rearranged. This is a very challenging task, with a huge number of combinations. In addition, the new values should not change or decrease the calculated sensitivity measure for negative emotions.

2. "As if Billy Bob Thornton, Nick Nolte, and Sean Penn names as the cast are not enough in a film, they do a swell job. The movie squeezed me yes but only psychologically. In short, a successful film noir, good work of Oliver Stone. [billy bob thornton nick nolte ve sean penn gibi isimlerin kadroda bulunması yetmiyormuş gibi bide döktürdükleri film film beni sıktı evet ama sadece psikolojik olarak kısacası başarılı bir kara film oliver stone un iyi işlerinden]".

The above review is marked manually as a positive emotion. However, the application assigned this review to a negative mood. In this review, the words in the dictionary and their probability values are as follows.:

$\begin{array}{ll}\text { good [iyi] } & 0,079452529 \\ \text { successful [başarılı] } & 0,220766411 \\ \text { psychological [psikolojik] } & 0,70862983 \\ \text { noir [kara] } & 0,798007993 \\ \text { but [ama] } & 0,839020825 \\ \text { only [sadece] } & 0,933505058\end{array}$

In this analysis, the words represent the review, but in part of the review, the user says "the movie squeezed me yes but only psychologically..." This indicates a negative mood. In other words, although the user indicates a positive state of emotion in the end, he also makes a negative discourse. Therefore, the algorithm will find the words "but", "only" and "psychological" and may consider their negative probability values and cause the result to be calculated negatively. To prevent this situation, transition-based sentence analysis is recommended. 
"every movie is beautiful [her film güzeldir]"

The above review is marked manually in case of positive emotion. However, the application could not assign this review to any state of emotion, in other words, it could not classify it. However, it should have been appointed because of the word "beautiful". At this point, it should be noted that the TMRED dictionary developed within the scope of the research consists of adjective/adverb-based words. Although the word "güzel" is included in this review, it also has the suffix "-dir; that is, the verb, or even the verb-noun. However, the word "güzel" [beautiful] is an adjective-based word when it is used without a suffix. For the reasons explained, an assignment to the interpretation could not be carried out. The situation needs to be examined within the framework of root-finding studies in sentimental analysis.

4. "Well, some movies start with such high score when newly added then fall to real score [ya bazı filmler yeni eklendiğinde böyle yüksek puanla başlıyor sonradan gerçek puanına düşer]"

The above review is marked manually as a negative emotion. However, the application assigned this review to positive emotion. The words "high", "new" and "real" in the interpretation are in the positive group in the TMRED dictionary. In this interpretation, only the word "düşer [falls]" indicates negativity but could not be evaluated by the algorithm because of the verb structure. In this case, the dictionary structure needs to be rearranged to include verbs and body analysis.

5. "It's a terrible remake movie. There are excellent players, but they were wasted, never showed themselves because of the script. It certainly doesn't deserve 7 [berbat bir yeniden çevrim mükemmel oyuncular var ama harcanmışlar hiç kendilerini senaryo yüzünden gösterememişler 7 yi kesinlikle hak etmiyor]".

The above review is marked manually as a negative emotion. However, the application assigned this review to positive emotion. In this review, the words in the dictionary and the probability values are as follows:

$\begin{array}{ll}\text { certainly [kesinlikle] } & 0,0001 \\ \text { excellent [mükemmel] } & 0,111991088 \\ \text { there are [var] } & 0,172251443 \\ \text { terrible [berbat] } & 0,989842728 \\ \text { but [ama] } & 0,839020825 \\ \text { never [hiç] } & 0,965074367\end{array}$

The first 3 of the above words are in positive and the last 3 are in negative group in the TMRED dictionary. However, the assignment was still incorrect with a small margin. This can be remedied by rearranging the probability values. More important is that the algorithm ignores the numerical data (7) in accordance with the rules of text mining. However, these data can significantly influence the assignment of interpretation to positive or negative mood. This can be prevented by formulas that convert numbers into text and the rules can be expanded in this direction.

\section{Conclusion}

This study is based on pragmatic analysis which is one of the five dimensions of natural language processing. The pragmatic analysis approach is used here to reveal users' perspectives, assessments, attitudes, needs, and the message they want to give, and their written language is preferred. Because of the interactive feature of today's internet environment, users express their opinions by writing reviews in media they interested. These written statements of users' reviews on the internet provided significant data for the natural language processing field and triggered analyzes to extract information from these data. Sentimental analysis can be said to be the result of such a trend.

Sentimental analysis is now expanding as applicable to all media formats such as textsound-image. The important thing is that the data contains a mood and the results that can be automatically detected from them benefit an area.

In this study, a sentimental analysis of the shared user reviews about films was done. The sensitivity measure obtained was $80,04 \%$ for positive emotion reviews and $65,02 \%$ for negative emotion reviews. The success of the assignment was higher in positive emotion reviews and the 
negative number of samples was much less than positive reviews. From this point of view, it can be said that better results can be obtained by expanding the dictionary in studies based on the mixed approach of dictionary-based technique and machine learning.

Information about positive or negative moods obtained from user reviews on a film, for example, about $60 \%$ of users have negative emotions about a movie- can be used for different purposes. Although this information does not represent all audience views, it is still an idea for users who have the potential to watch the film on the individual side. In addition, film actors, producers, advertisers, critics and so on are a very important source of feedback. It provides them with new and expandable opportunities to develop more effective strategies and contributes to the limitation of feedback in the traditional mass media "cinema".

Finally, the improper results of the developed application have been discussed together with the different reasons causing the error and suggestions have been made. Although the initial objective is largely achieved, it is useful to consider these recommendations for future studies. This application, which was developed based on unsupervised learning, is expected to contribute to the natural language processing literature in Turkish language.

\section{References}

[1] Adalı, E. (2013). Doğal Dil İşleme. Türkiye Bilişim Vakfı Bilgisayar Bilimleri ve Mühendisliği Dergisi(7).

[2] Amasyalı, M., Balcı, S., Varlı, E. N., \& Mete, E. (2012, 12). Türkçe Metinlerin Sınıflandırılmasında Metin Temsil Yöntemlerinin Performans Karşılaştırılması. EMO BíLiMSEL DERGi, 2(4), p. 1-10.

[3] Aytekin, Ç. (2013, March). An Opinion Mining Task in Turkish Language: A Model for Assigning Opinions in Turkish Blogs to the Polarities. Journalism and Mass Communication, 3(3), p. 179-198.

[4] Bell, T. (2017, 06 27). Terena Bell Twitter Account. Address: https://twitter.com/terenabell/status/879717843834724353?lang=ca

[5] Culver, A. (2019, 04 09). The Dartmouth. Students develop "Left on Read" app to track texting habits. Address: https://www.thedartmouth.com/article/2019/04/students-develop-left-on-readapp-to-track-texting-habits

[6] Eryiğit, G. (2014). ITU Turkish NLP Web Service. 14th Conference of the European Chapter of the Association for Computational Linguistics EACL 2014. Gothenburg.

[7] Gleason, J. B. (2005). The Development of Language. Boston: Pearson Education.

[8] Kamvar, S., \& Harris, J. (2011). We Feel Fine and Searching The Emotional Web.

Proceedings of The Fourth ACM International Conference On Web Search and Data Mining, (p. 117-126). Hong Kong.

[9] Kaynar, O., Yıldız, M., Görmez, Y., \& Albayrak, A. (2016). Makine Öğrenmesi Yöntemleri ile Duygu Analizi. International Artificial Intelligence and Data Processing Symposium (IDAP'16), (p. 234-241). Malatya.

[10] Kim, D., \& Kim, S. (2018). Newspaper journalists' attitudes towards robot journalism. Telematics and Informatics(35), s. 340-357. doi:10.1016/j.tele.2017.12.009

[11] Li, W., Xu, K., Qi, J., \& Ding, X. (2018). A Natural Language Processing Method of Chinese Instruction for Multi-legged Manipulating Robot. IEEE International Conference on Robotics and Biomimetics, (p. 2171-2176). Kuala Lumpur.

[12] Liu, B. (2012). Sentiment Analysis and. San Rafael: Morgan \& Claypool Publishers.

[13] Naeun, L., Kirak, K., \& Yoon, T. (2017). Implementation of robot journalism by programming custombot using tokenization and custom tagging. 19th International Conference on Advanced Communication Technology (ICACT), (p. 566-570). Kwangwoon Do. doi:10.23919/ICACT.2017.7890154

[14] Nanda, C., Dua, M., \& Nanda, G. (2018). Sentiment Analysis of Movie Reviews in Hindi Language Using Machine Learning. International Conference on Communication and Signal Processing (ICCSP) , (p. 1069-1072). Chennai. 
[15] Nasukawa, T., \& Yi, J. (2003). Sentiment analysis: Capturing avorability using natural language processing. Proceedings of the K-CAP-03, 2nd Int Conference on Knowledge Capture.

[16] Oflazer, K. (2016). Türkçe ve Doğal Dil İşleme. Türkiye Bilişim Vakfı Bilgisayar Bilimleri ve Mühendisliği Dergisi, 5(2), p. 1-12. Address: https://dergipark.org.tr/download/articlefile/207207

[17] Periscopic. (2019, 5 4). On the Trump Emoto-Coaster. Address: https://emotions.periscopic.com/

[18] Permatasari, R. I., Fauzi, M. A., Adikara, P. P., \& Lukmana Sari, E. D. (2018). Twitter Sentiment Analysis of Movie Reviews using Ensemble Features Based Naïve Bayes. International Conference on Sustainable Information Engineering and Technology (SIET), (s. 92-95). Malang. doi:10.1109/SIET.2018.8693195

[19] Ren, R., Wu, D. D., \& Liu, T. (2019, 03). Forecasting Stock Market Movement Direction Using Sentiment Analysis and Support Vector Machine. IEEE SYSTEMS JOURNAL, 13(1), s. 760770.

[20] Rosa, R. L., Schwartz, G. M., Ruggiero, W. V., \& Rodr'ıguez, D. Z. (2019, 4). A KnowledgeBased Recommendation System That Includes Sentiment Analysis and Deep Learning. IEEE TRANSACTIONS ON INDUSTRIAL INFORMATICS, 15(4), p. 2124-2135.

[21] Sentiment Analysis Research Group. (2019). SentiLab. Address: http://sentilab.sabanciuniv.edu/

[22] Solangi, Y. A., Solangi, Z. A., Aarain, S., Abro, A., Mallah, G. A., \& Shah, A. (2018). Review on Natural Language Processing (NLP) and Its Toolkits for Opinion Mining and Sentiment Analysis. IEEE 5th International Conference on Engineering Technologies \& Applied Sciences. Bangkok.

[23] Song, Y., Gu, K., Li, H., \& Sun, G. (2017). A Lexical Upadating Algorithm for Sentiment Analysis on Chinese Movie Reviews. Fifth International Conference on Advanced Cloud and Big Data, (p. 188-193). Shanghai. doi:10.1109/CBD.2017.40

[24] Sütçü, C., \& Aytekin, Ç. (2018). Veri Bilimi. İstanbul: Paloma.

[25] Traylor, T., \& Straub, J. (2019). Classifying Fake News Articles Using Natural Language Processing to Identify In-Article Attribution as a Supervised Learning Estimator. IEEE 13th International Conference on Semantic Computing (ICSC) (p. 445-449). California: IEEE Computer Society. doi:10.1109/ICSC.2019.00086

[26] Vural, A., Cambazoğlu, B., Şenkul, P., \& Tokgöz, Z. (2013). A Framework for Sentiment Analysis in Turkish: Application to Polarity Detection of Movie Reviews in Turkish. E. Gelenbe, \& R. Lent içinde, Computer and Information Sciences III (p. 437-445). London: Springer.

[27] We Feel Fine. (2019, 05 06). We Feel Fine. Methodology. Address: http://wefeelfine.org/methodology.html

[28] Withanage, P., Liyanage, T., Deeyakaduwe, N., Dias, E., \& Thelijjagoda, S. (2018). Road Navigation System Using Automatic Speech Recognition (ASR) And Natural Language Processing (NLP). 2. I. (R10-HTC) (Dü.). içinde Malambe: IEEE. doi:10.1109/R10HTC.2018.8629859

[29] Zemberek. (2019, 5 3). Zemberek NLP. Address: http://zembereknlp.blogspot.com/ 